\title{
The effects of a sudden decrease or increase in daylength on prolactin secretion in the ram
}

\author{
G. A. Lincoln, A. S. McNeilly and C. L. Cameron \\ M.R.C. Unit of Reproductive Biology, 2 Forrest Road, Edinburgh EHI $2 Q W, U . K$.
}

\begin{abstract}
Summary. Six adult Soay rams were preconditioned to an artificial lighting regimen of alternating 4-month periods of long (16L:8D) and short days (8L:16D) for at least 10 months before blood samples were collected at hourly intervals for $24 \mathrm{~h}$ at various times. The abrupt change from long to short days resulted in a progressive decrease in plasma levels of prolactin, while that from short to long days had the reverse effect; the first response to the light changes was rapid, beginning within 6 days. During the periods of high secretion there was a 24 -h cycle in plasma prolactin concentrations, with a peak in both the early dark and early light phases of each day. Changes in the relative magnitude of these peaks were observed in relation to the long-term alteration in prolactin secretion. Plasma levels of FSH were also measured and a close inverse relationship between gonadotrophin and prolactin secretion was observed.
\end{abstract}

\section{Introduction}

In the ram there are conspicuous changes in the blood levels of prolactin during the year, the highest levels occurring during the summer months and the lowest levels in the winter (Ravault, 1976). The timing of these seasonal changes can be readily modified by altering the photoperiod (Pelletier, 1973) and in the natural situation the annual variation in daylength is probably the principal environmental cue dictating the timing of the seasonal prolactin cycle. Photoperiods which favour prolactin secretion (long days) have the reverse effect on gonadotrophin secretion (Pelletier \& Ortavant, 1975; Lincoln, Peet \& Cunningham, 1977), and under natural conditions, therefore, there is an inverse relationship between prolactin and gonadotrophin release.

In the present study this relationship is investigated in more detail by measuring prolactin levels in blood samples collected from rams, living under artificial lighting conditions, in which gonadotrophin secretion and testicular activity have already been carefully documented (Lincoln et al., 1977; Lincoln \& Peet, 1977).

\section{General Methods}

Adult rams of the Soay breed were exposed to alternating 16-week periods of 'long' days (16 h light: $8 \mathrm{~h}$ darkness, $16 \mathrm{~L}: 8 \mathrm{D})$ and 'short' days $(8 \mathrm{~L}: 16 \mathrm{D})$ before the initiation of experiments which investigated the effects of a sudden decrease (Exp. I) or a sudden increase (Exp. II) in daylength. Blood samples were collected from the animals by using a jugular cannula which was inserted the day before sampling. On each occasion particular care was taken not to disturb the animals, which remained in their normal pens. Faint red illumination from a torch was used to aid blood collections during the dark phase of each 24 -h cycle.

The blood samples were centrifuged immediately and the plasma stored at $-20^{\circ} \mathrm{C}$ until assayed for ovine prolactin with a double-antibody radioimmunoassay (McNeilly \& Andrews, 1974; Lamming, Moseley \& McNeilly, 1974). The sensitivity of the assay was $2.0 \mathrm{ng} / \mathrm{ml}$, with NIH-P-S9 as reference standard and all samples from one animal were measured in duplicate in a single assay.

Concentrations of LH, FSH and testosterone were also measured in these plasma samples and these results have been reported (Lincoln et al., 1977). Some of the mean values for plasma FSH are given herein to allow direct comparison with the prolactin results. 


\section{Experiment I}

\section{Methods}

Six rams preconditioned to the alternating 16-week photoperiod changes for 2 years were studied over a 15-week period during which the daylength was abruptly changed from long to short days by advancing the time of 'lights out' by $8 \mathrm{~h}$. Blood samples were collected from each ram at hourly intervals for 24 h on Days 6, 12, 19, 26, 33, 54 and 100, as well as on Day 0 (the last day of a 16-week period of $16 \mathrm{~L}: 8 \mathrm{D})$.

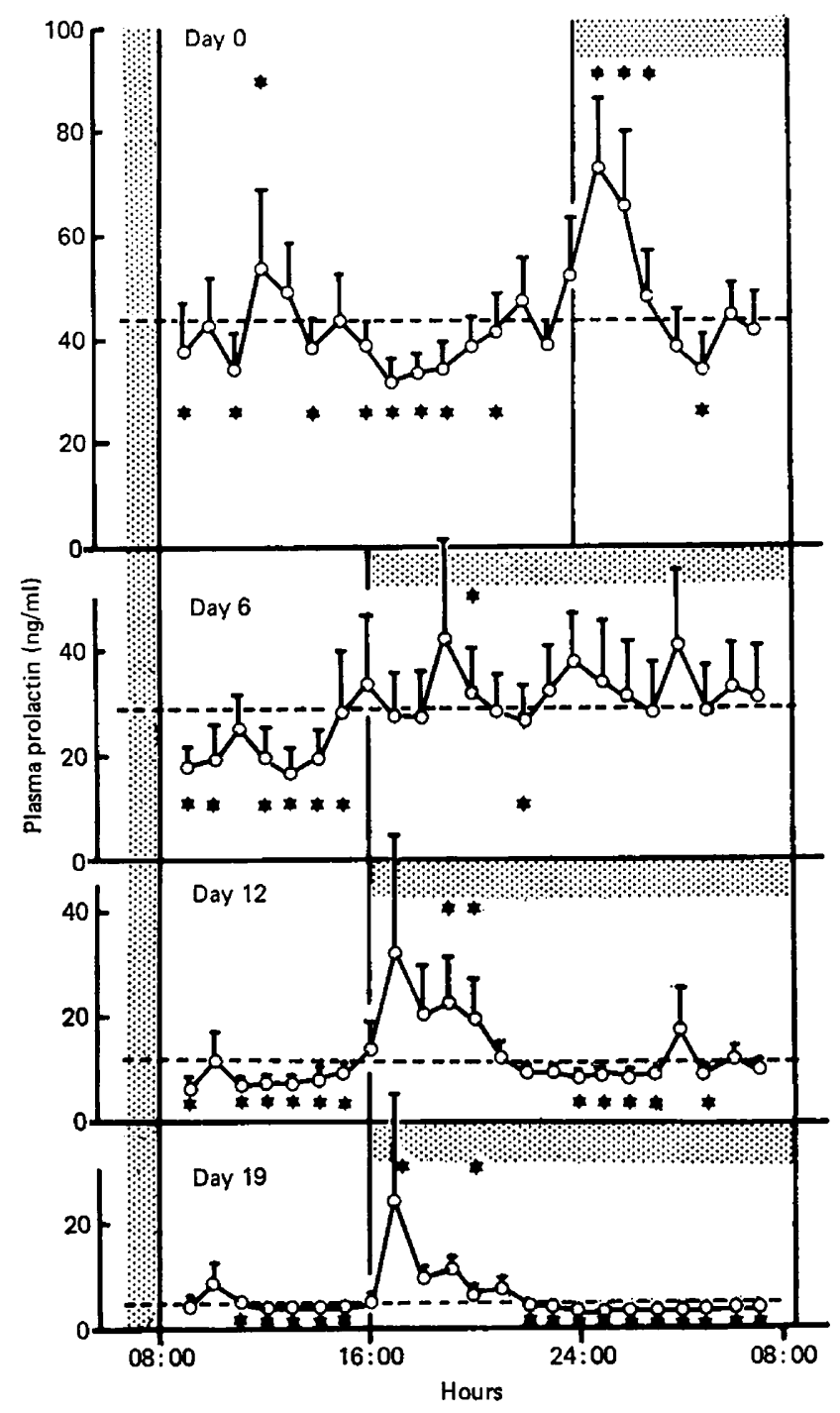

Text-fig. 1. Plasma levels of prolactin (ng equiv. NIH-P-S9: mean \pm s.e.m.) for 6 Soay rams sampled hourly for $24 \mathrm{~h}$ on one occasion at the end of a 16-week period of long days (Day 0 ) and on 3 occasions during short days (Days 6, 12 and 19). Values marked by an asterisk (*) indicate the times during each day when at least 5 of the animals had prolactin levels above or below the daily mean of each individual. The horizonal broken line indicates the mean prolactin level for the group on that day and the stippling shows the dark phase of each 24-h cycle. 
(|W/6u) HS $\mathrm{H}$ euseld

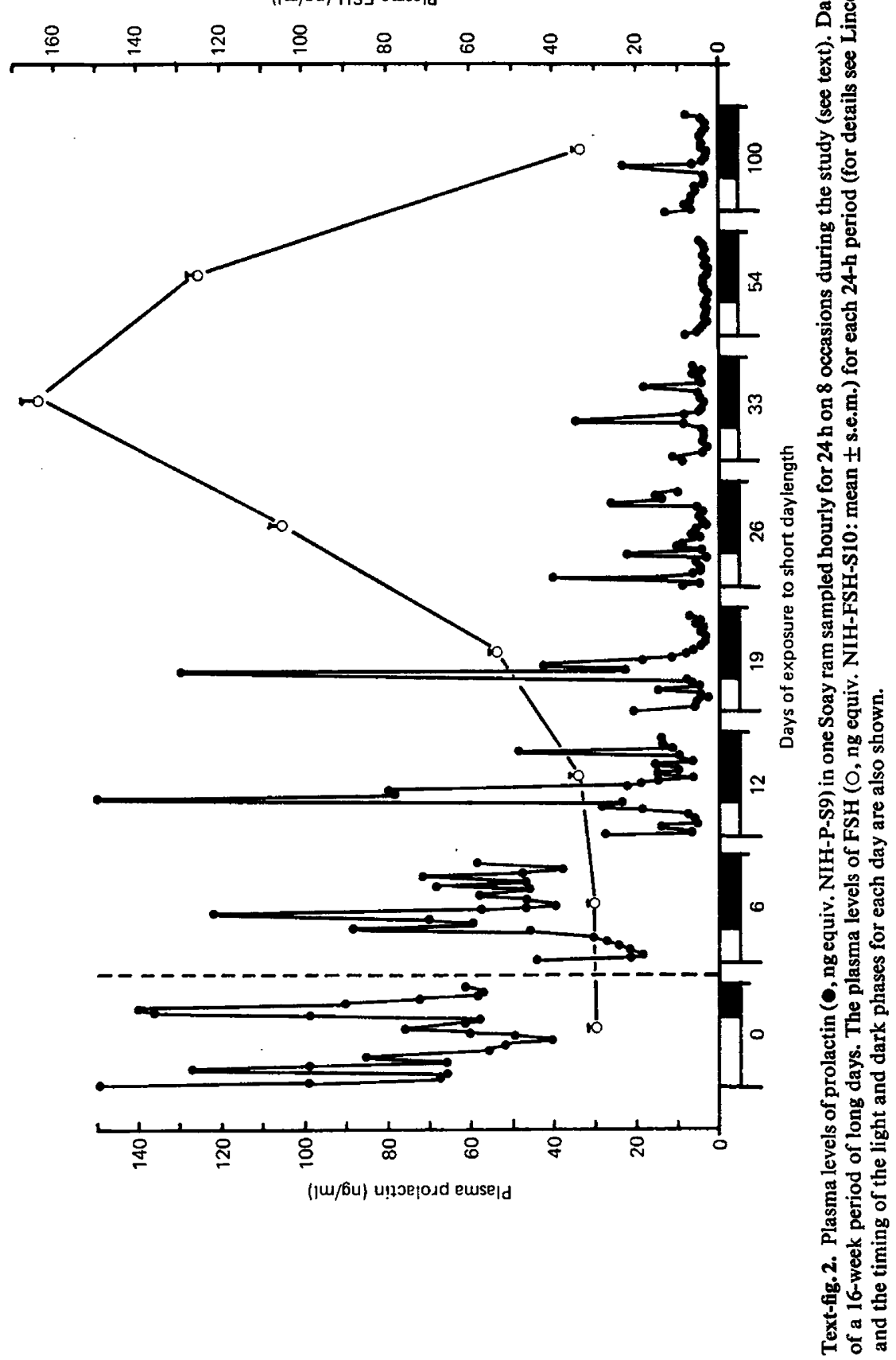




\section{Results}

The changes in plasma prolactin concentrations for all six rams on Days $0,6,12$ and 19 are shown in Text-fig. 1 and all results for one ram are given in Text-fig. 2.

Prolactin levels on Day 0 (long days) were universally high (24-h group mean $=43 \cdot 8 \pm 6 \cdot 6$ (s.e.m.) $\mathrm{ng} / \mathrm{ml})$. On Day 6 after the change to short days prolactin levels were significantly decreased $(P<0 \cdot 01$, paired $t$ test) in all animals (24-h group mean $=28.4 \pm 6.8 \mathrm{ng} / \mathrm{ml}$ ), and the decline continued, the 24-h group means on Day 12 and 19 being $11.7 \pm 3.4$ and $5.6 \pm 1.8 \mathrm{ng} / \mathrm{ml}$ respectively. The prolactin levels remained low from Day $26(<4.0 \mathrm{ng} / \mathrm{ml})$ onwards.

In the early part of the study when the rams were hyperprolactinaemic (Days $0,6,12$ and 19) there

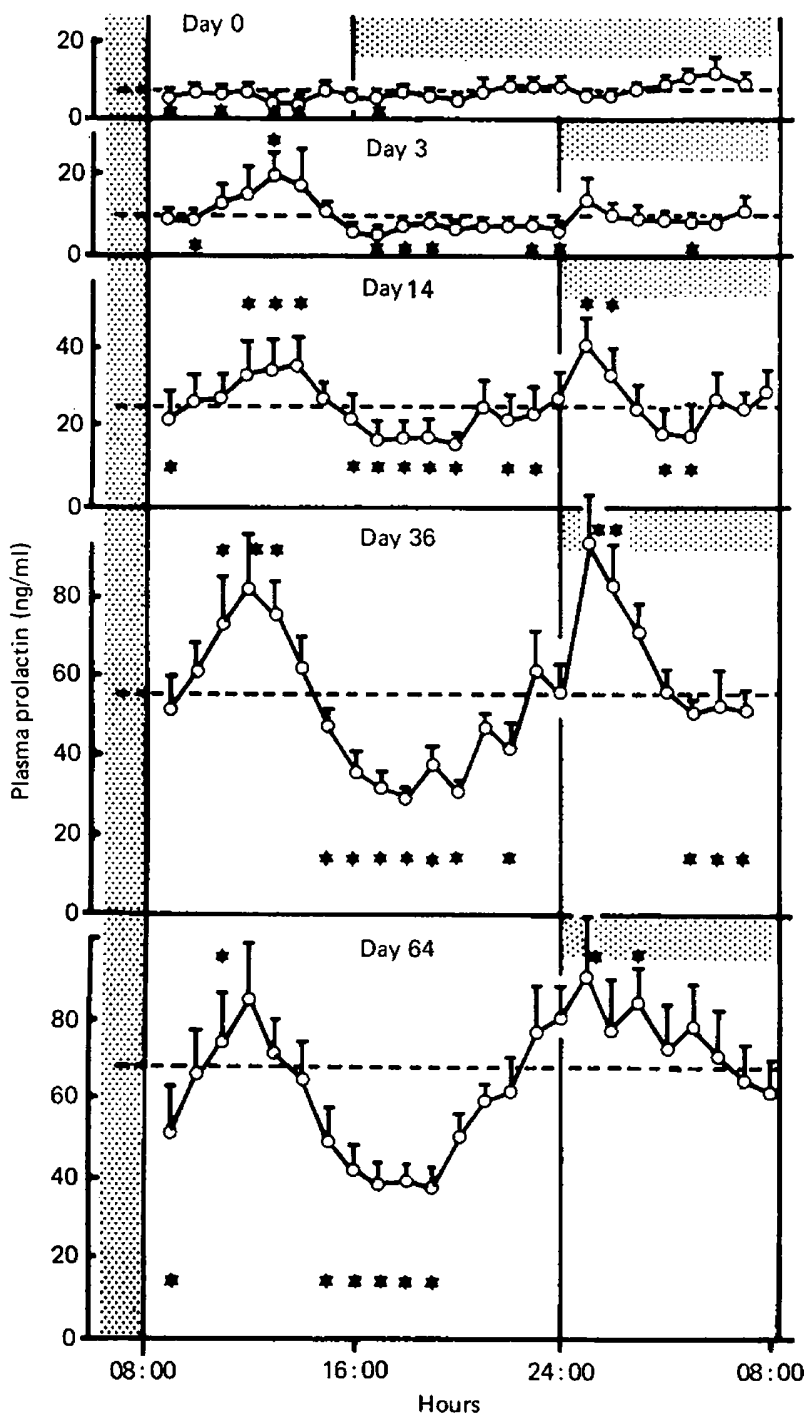

Text-fig. 3. Plasma levels of prolactin (ng equiv. NIH-P-S9: mean \pm s.e.m.) for 6 Soay rams sampled hourly for $24 \mathrm{~h}$ on one occasion at the end of a 16-week period of short days (Day 0 ) and on 4 occasions during a period of long days (Days 3, 14, 36 and 64). Values marked by an asterisk ( ${ }^{*}$ ) indicate the times during each day when at least 5 of the animals had prolactin levels above or below the daily mean of each individual. The horizontal broken line indicates the mean prolactin level for the group on that day, and the stippling shows the dark phase of each 24-h cycle. 


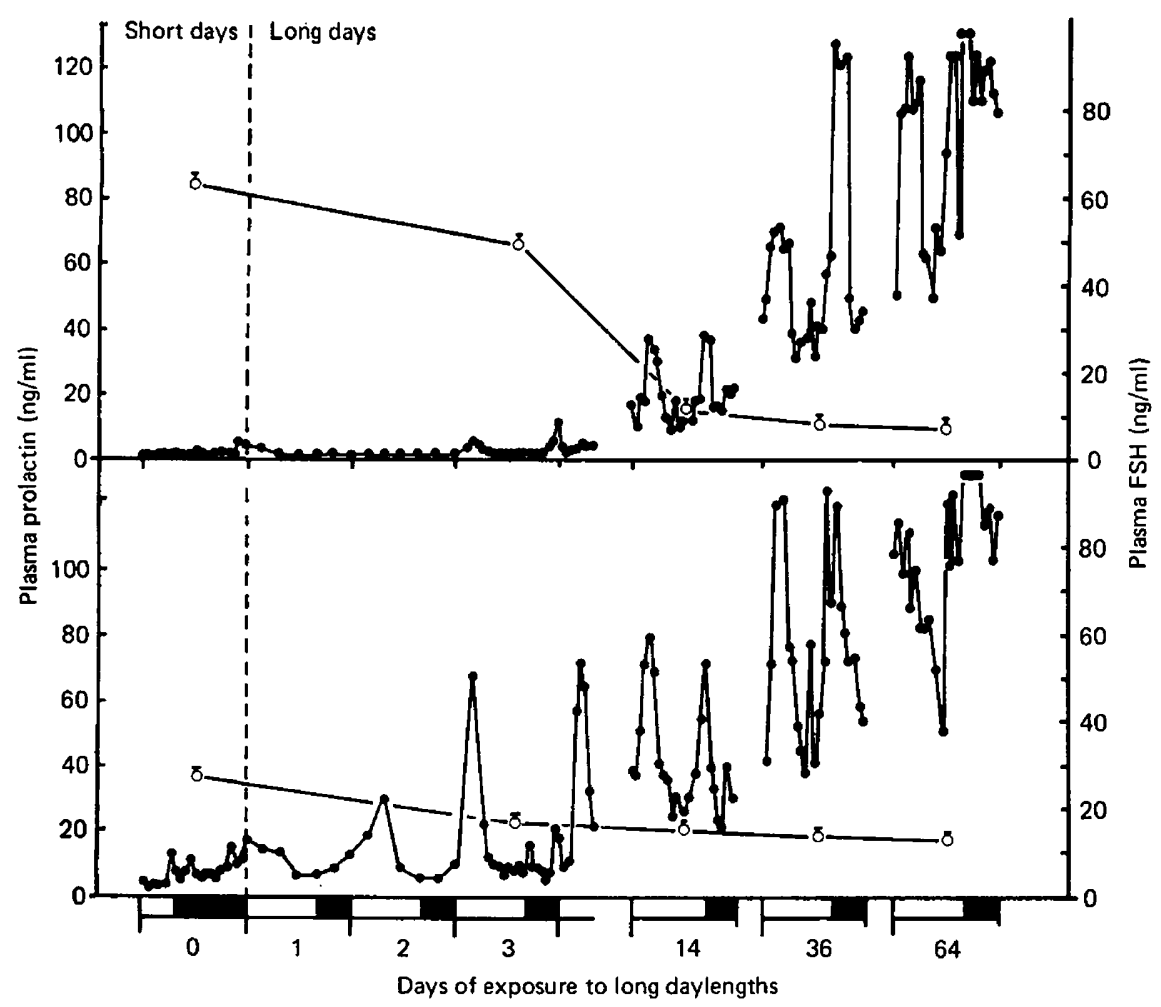

Text-fig. 4. Plasma levels of prolactin (e, ng equiv. NIH-P-S9) in two adult Soay rams sampled on several occasions after a change from short to long days. Day 0 is the last day of a 16-week period of short days. The plasma levels of FSH (O, ng equiv. NIH-FSH-S10: mean \pm s.e.m.) for each 24-h period (for details see Lincoln $e t$ al., 1977) and the timing of the light and dark phases of each day are also shown.

were short-term changes in the levels of prolactin related to the light/dark cycle in each 24-h period (see Text-fig. 1): peak prolactin levels occurred during the early part of the dark phase. Since the change from long to short days was achieved by altering the timing of lights out, the nocturnal rise in prolactin levels occurred at different times of day under long and short days. In addition to the darkphase peak, a smaller peak of prolactin occurred in the early hours of the light phase of the 24-h cycle (Text-fig. 1). This peak occurred at about the same time throughout the study until after Day 26 when it was fully depressed.

\section{Experiment II}

\section{Methods}

The same 6 rams had experienced the 16-week alternating photoperiod regimen for 10 months when they were studied for 9 weeks during a change from short $(8 \mathrm{~L}: 16 \mathrm{D})$ to long days $(16 \mathrm{~L}: 8 \mathrm{D})$ ). The light change was again abrupt and involved delaying 'lights out' by $8 \mathrm{~h}$. Blood samples were collected at hourly intervals for $24 \mathrm{~h}$ on Days 3,14, 36 and 64 following the beginning of long days, as well as on Day 0 (the last day of 16-week period of 8L:16D). Additional blood samples were also collected at 4-h intervals from Days 0 to 3.

\section{Results}

The overall results for all 6 rams are shown in Text-fig. 3 and the individual results for 2 animals are given in Text-fig. 4. 
Prolactin levels were low on Day 0 (end of short days; 24 -h group mean $=8 \cdot 8 \pm 4 \cdot 0$ (s.e.m.) ng/ml), but within 3 days of exposure to long days prolactin levels in 4 of the 6 rams had increased significantly (group mean $=9.8 \pm 3.5 \mathrm{ng} / \mathrm{ml}$; see Text-fig. 4 ) and by Day 14 this increase was evident in all animals (group mean $25.6 \pm 6.4 \mathrm{ng} / \mathrm{ml}: P<0.01$ compared to Day 0, paired $t$ test). On Days 36 and 64 the prolactin levels were $56 \cdot 0 \pm 6.9$ and $67.9 \pm 10.9 \mathrm{ng} / \mathrm{ml}$ respectively.

During each $24-\mathrm{h}$ period after the increase in prolactin levels there were short-term changes in prolactin secretion related to the light/dark cycle. Two periods of peak secretion were recognized, one early in the light phase and one early in the dark phase (Text-fig. 3). During the initial response to the change in photoperiod (Days 3 and 14) it was the daytime peak which was most conspicuous, appearing as early as Day 2 (see Text-figs 3 and 4), while later the night-time peak became more obvious.

\section{Discussion}

The blood samples from the present studies have been assayed for LH and FSH (Lincoln \& Peet, 1977; Lincoln et al., 1977), and some of the FSH results are illustrated in Text-figs 2 and 4. The change from long to short days resulted in an increase in the plasma levels of $\mathrm{LH}$ and $\mathrm{FSH}$, while the change from short to long days had the reverse effect. These changes are precisely opposite to those described for prolactin; e.g. when the rams were hyperprolactinaemic under long days gonadotrophin secretion was minimal, testicular activity was reduced and the animals were sexually inactive (Lincoln \& Davidson, 1977), but when the prolactin levels decreased under the influence of short days resurgence of sexual activity occurred. These observations emphasize a very close inverse relationship between prolactin and gonadotrophin secretion, but whether this is a causal relationship, as suggested when there is infertility due to hyperprolactinaemia (Fang, Refetoff \& Rosenfield, 1974; Thorner, McNeilly, Hagan \& Besser, 1974), is not clear. The diurnal pattern in prolactin levels is not inversely correlated with that for gonadotrophins (see Lincoln \& Peet, 1977, for diurnal rhythm in LH and FSH), and short-term fluctuations in prolactin and gonadotrophin levels are apparently independent. Similarly, after prolonged exposure to short days (Days 54 and 100, Text-fig. 2) plasma FSH levels decline markedly while prolactin levels remain low, indicating the lack of a relationship at this time. The functional significance of the changes in prolactin secretion in the ram remains obscure.

A nocturnal rise in prolactin levels similar to that seen in the ram (see also Ravault et al., 1976) occurs in man (Sassin, Frantz, Kapen \& Weitzman, 1973) and in the rat (Dunn, Arimura \& Scheving, 1972). In man, the increase has been shown to be related to sleep, but this does not appear to be the case in the ram because the animals in the present experiment generally showed the most conspicuous signs of sleep late in the dark phase of the 24-h cycle (Lincoln et al., 1977), at a time not coincident with the increased prolactin levels. In the present study the timing of the nocturnal rise in prolactin remained constant in relation to the time of 'lights' on, indicating that the transfer from light to darkness is important in determining the timing of the nocturnal rise. Similarly, the transfer from darkness to light may be important for the timing of the small daytime rise in prolactin levels, since the timing of this remained constant. These diurnal changes in prolactin levels that are lost under prolonged exposure to short days reappear when rams are transferred to long days and prolactin secretion increases again.

\section{References}

Dunn, J.D., Arimura, A. \& Scheving, L.E. (1972) Effect of stress on circadian periodicity in serum $\mathbf{L H}$ and prolactin concentration. Endocrinology 90, 2933.

FANG, V.S., Refetoff, S. \& Rosenfield, R.L. (1974) Hypogonadism induced by a transplantable, prolactin-producing tumour in male rats. Hormonal and morphological studies. Endocrinology 95, 991-998.
LAmming, G.E., Moseley, S.R. \& MCNeilly, J.R. (1974) Prolactin release in the sheep. J. Reprod. Fert. 40, $151-168$.

Lincoln, G.A. \& Davidson, W. (1977) The relationship between sexual and aggressive behaviour, and pituitary and testicular activity during the seasonal sexual cycle of rams, and the influence of photoperiod. $J$. Reprod. Fert. 49, 267-276. 
Lincoln, G.A. \& Peet, M.J. (1977) Photoperiodic control of gonadotrophin secretion in the ram: a detailed study of the temporal changes in plasma levels of follicle-stimulating hormone, luteinizing hormone and testosterone following an abrupt switch from long to short days. J. Endocr. 74, 355-367.

Lincoln, G.A., Peet, M.J. \& CunNingham, R.A. (1977) Seasonal and circadian changes in the episodic release of follicle-stimulating hormone, luteinizing hormone and testosterone in rams exposed to artificial photoperiods. J. Endocr. 72, 337-349.

McNeIlLy, A.S. \& ANDREws, P. (1974) Purification and characterization of caprine prolactin. J. Endocr. 60, 359-367.

Pelletier, J. (1973) Evidence for photoperiodic control of prolactin release in rams. J. Reprod. Fert. 35, 143147.

Pelletier, J. \& Ortavant, R. (1975) Photoperiodic control of $\mathrm{LH}$ release in the ram. 1. Influence of in- creasing and decreasing light photoperiods. Acta endocr., Copenh. 78, 435-441.

RavaulT, J.P. (1976) Prolactin in the ram: seasonal variation in the concentration of blood plasma from birth to three years old. Acta endocr., Copenh. 83, 720-725.

Ravault, J.P., Daveau, A., Garnier, D., Pelletier, J., De Reviers, M.M., Terqui, M. \& Ortavant, R. (1976) Influence of some light pulses on the daily variation of prolactin secretion in the ram. Proc. 8 th Int. Congr. Anim. Reprod. \& A.I., Krakow, Vol. 4, pp. 81-83.

Sassin, J.F., Frantz, A.G., Kapen, S. \& Weitzman, E.D. (1973) The nocturnal release of human prolactin is dependent on sleep. J. clin. Endocr. Metab. 37, 436-440.

Thorner, N.O., McNeilly, A.S., Hagan, C. \& Besser, G.M. (1974) Long term treatment of galactorrhoea and hypogonadism with bromocryptine. Br. med. $J$. 2, 419-422.

Received 17 October 1977 